\title{
Fútbol y cine en el franquismo: la utilización política del héroe deportivo en la España de Franco
}

\author{
Juan Antonio SIMÓN SANJURJO \\ Centro de Estudios Olímpicos, Universidad Autónoma de Barcelona \\ jasimonsanjurjo@hotmail.com
}

Recibido: 19 de julio de 2012.

Aceptado: 2 de septiembre de 2012.

\begin{abstract}
Resumen
La industria cinematográfica durante los años cincuenta aprovechará el enorme impacto del fútbol en la sociedad española, para producir un amplio número de películas ambientadas en este deporte. Uno de los principales reclamos para los espectadores será la participación de los dos grandes ídolos futbolísticos de la época en varias películas: Ladislao Kubala y Alfredo Di Stéfano. Ambos transformarán la historia de sus respectivos clubes, FC Barcelona y Real Madrid, y serán tentados por el cine para protagonizar varios filmes. Este artículo pretende analizar las dos películas que tendrán a estos jugadores como actores principales (Los ases buscan la paz y Saeta rubia), incidiendo en cómo se presentará en el cine la imagen del nuevo héroe deportivo. Al mismo tiempo, el texto tratará de descubrir cuáles fueron los elementos que configurarán el modelo masculino de éxito durante el franquismo.
\end{abstract}

Palabras clave: Fútbol;historia; cine; ídolo deportivo.

\section{Football and cinema in the francoism: the political utilization of the sporting heroes in Franco's Spain}

\begin{abstract}
The film industry during the 50's took advantage of the huge impact of football in the Spanish society to produce a large number of films about this sport. One of the main attractions for the audience was the performance of the greatest football idols in several films: Ladislao Kubala and Alfredo Di Stéfano. Both footballers changed the history of their clubs, FC Barcelona and Real Madrid, and were tempted to starring some films. This paper aims to analyze the two films that have these football players like main actors (Los ases buscan la paz y Saeta rubia), to insist how the films show the image of the new sports hero. At the same time, the text try to discover what were the elements that shape the masculine model of success during the francoism.
\end{abstract}

Key words: Football; history; cinema; a sport idol.

\section{Referencia normalizada}

Simón Sanjurjo, J. A. (2012). Fútbol y cine en el franquismo: la utilización política del héroe deportivo en la España de Franco. Historia y Comunicación Social, Vol. 17, páginas 69-84.

Sumario: 1. Introducción y metodología; 2. Cine y franquismo en la década de los cincuenta; 3. El renacimiento del fútbol como espectáculo de masas; 4. Cine, fútbol y anticomunismo en Los ases buscan la paz; 5. De la Saeta rubia a La batalla del domingo: principio y fin de una estrella; 6. A modo de conclusión; 7. Bibliografía. 


\section{Introducción y metodología}

Durante los años cincuenta cine y fútbol, históricos competidores dentro de un mercado del ocio que ya comenzaba a mostrar claros signos de recuperación después de una larga posguerra, se darán la mano gracias al intento de explotar la proyección social de algunas de las grandes estrellas del fútbol español en varias producciones cinematográficas. Este texto pretende analizar dos de las películas más representativas de lo que podríamos denominar como el ciclo fílmico-futbolístico del franquismo. Es necesario hacer constar el profundo olvido que ha existido por parte del mundo académico respecto a la relación entre cine y deporte, y en concreto, a la necesidad acuciante de nuevos trabajos que analicen desde múltiples perspectivas la utilización de un fenómeno social como el fútbol a través del cine.

La película Campeones (1942), que dirigirá Ramón Torrado y que contará con la actuación de algunos nombres propios de la historia del fútbol español, como Ricardo Zamora, Guillermo Gorostiza y Jacinto Quincoces, se puede definir como el antecedente de un ciclo cinematográfico que tendrá su continuación en obras como El sistema Pelegrín (1952), Once pares de botas (1954), El Fenómeno (1956), El hincha (1957), El ángel está en la cumbre (1958), La quiniela (1960), Los económicamente débiles (1960), Tres de la Cruz Roja (1961), Los de la furia (1962) y La batalla del domingo (1963). Antes de la guerra civil, el primer acercamiento de las estrellas del balón al cine había llegado con iPor fin se casa Zamora! (1927), película dirigida por José Fernández que tendrá en el portero Ricardo Zamora a su principal protagonista compartiendo cartel con la actriz Emilia Donnay (Simón, 2011: 456).

Dentro del grupo anterior, se incluyen por meritos propios dos películas que representan por encima de las demás el innegable interés que el cine mostrará hacia la utilización de la imagen de las grandes estrellas del fútbol: Los ases buscan la paz (1954) y Saeta rubia (1956). Encuadradas ambas en el marco cronológico que identifica al mencionado ciclo cinematográfico, la primera de ellas estará protagonizada por el ídolo del FC Barcelona, Ladislao Kubala, mientras que Saeta rubia tendrá como actor principal al argentino Alfredo Di Stéfano, el futbolista que logrará cambiar la historia del Real Madrid. El estudio en profundidad de ambos títulos centrará el contenido de este artículo (Gisbert, 2002; Romaguera, 2003; Marañón, 2005).

Es posible que a nivel técnico estas películas no tengan grandes aspectos que reseñar, pero en cambio, son magníficos ejemplos de cómo este tipo de obras se convierten en herramientas perfectas para difundir a las masas el modelo masculino de éxito que promovía el franquismo. Desde los años cincuenta los nuevos ídolos de la juventud serán las estrellas del balón, a los que no se les reconocerá únicamente por sus grandes condiciones como deportistas, sino que también reunirán un conjunto de valores humanos que les permitían convertirse en referentes para el conjunto de la sociedad, dentro y fuera del terreno de juego.

El franquismo tratará de convertir el cine en un elemento fundamental para la construcción de identidades y modelos sociales, logrando de este modo conseguir 
aglutinar a las diferentes tendencias sociales y políticas conservadoras. Al mismo tiempo, el impacto masivo del cine en la sociedad le permitirá alcanzar una importancia decisiva como herramienta ideológica para el Estado, preocupándose desde el primer momento en su estricto control y su utilización como medio propagandístico y educador de las masas durante la dictadura.

La estructura del texto partirá de un análisis inicial de la situación del cine español en los años cincuenta, para posteriormente definir el contexto deportivofutbolístico que vivía España durante este mismo periodo. A continuación, se pasará al estudio pormenorizado de cada película y al impacto de dichos filmes en la sociedad. Por último, el artículo concluirá definiendo cuáles son los principales rasgos que caracterizan para el franquismo al estereotipo cinematográfico del héroe deportivo, en base a los elementos que aparecen en las dos películas examinadas.

\section{Cine y Franquismo en la década de los cincuenta}

Para contextualizar adecuadamente el ciclo fílmico que tratará de explotar durante este periodo el protagonismo de un espectáculo de masas como el fútbol, es necesario aproximarnos al estudio de los elementos y factores que de forma general definieron la industria cinematográfica española durante los años cincuenta y que influirán directamente en las características de este grupo de películas que tendrán como argumento principal el mundo del fútbol. El inicio de la década mostrará la quiebra definitiva del modelo hipertrofiado de cine histórico, que tendrá en las tres películas dirigidas por Juan de Orduña, Agustina de Aragón, La leona de Castilla y Alba de América, sus últimas obras más significativas. Será precisamente este último título, el que centre la polémica en 1951cuando José María García Escudero, el primer Director General de Cinematografía y Teatro, no le conceda la categoría de "interés nacional" al proyecto cinematográfico de Orduña, pese a contar con el auspicio del propio Carrero Blanco y la producción de Cifesa. A lo anterior, se había unido el fuerte malestar provocado por la concesión previa de esta categoría a Surcos, un film de José Antonio Nieves Conde fuertemente influenciado por la corriente neorrealista y que afrontaba aspectos incómodos para el Régimen como la inmigración, el desempleo o la prostitución. Ambas medidas influirán directamente en la dimisión de García Escudero en febrero de 1952 y el posterior traspaso de su cargo a Joaquín Argamasilla, cerrando por el momento las posibilidades de definir una nueva política cinematográfica (Filmoteca, 2003).

Continuando con el breve análisis de los principales géneros que definieron el cine español durante estos años, al mencionado final del ciclo histórico y literario se opondrá la continuidad del género de comedia y el musical folclórico con sus particulares líneas de evolución. La comedia de los cincuenta incidirá en la utilización de registros que hundían sus raíces en la picaresca y el sainete, como demuestran títulos como Historias de la radio (1955) de Sáenz de Heredia, o Los gamberros (1954), Los tramposos (1959), Manolo guardia urbano (1956) y Atraco a las tres (1962). La evolución del género llegará con la denominada comedia del desarrollismo y filmes 
como Las chicas de la Cruz Roja (1958) de R. J. Salvia, Viaje de novios de León Klimovsky, El día de los enamorados dirigida por Fernando Palacios, junto con varios títulos de Pedro Lazaga como Ana dice sí, Luna de verano y La gran familia (Herrera, 2005).

El cine musical folclórico, el segundo de los géneros que definen esta década, seguirá apegado a una tradición andalucista que parecía atraer a los públicos más populares, con argumentos que giraban alrededor de una trama simple de claro carácter cómico o melodramático, y con el protagonismo de alguna de las grandes estrellas de la canción andaluza, como ocurrirá con la interpretación de Carmen Sevilla y Jorge Mistral en Un caballero andaluz (1954). Será a partir de 1957 con el gran éxito comercial de El último cuplé y la enorme popularidad que alcanzará Sara Montiel, cuando se inicie el conocido ciclo del "cuplé" al que se pueden incorporar otros títulos de gran impacto en las taquillas como La violetera (1958), Aquellos tiempos del cuplé (1958), Mi último tango (1960), Y después del cuplé (1959), etc. (Payán, 2002).

Pero el verdadero éxito comercial llegará con el denominado "cine con niño", en donde la presencia de estrellas infantiles o "niños prodigio" se convertirá en el principal reclamo de películas de la transcendencia de Marcelino, pan y vino (1954), El pequeño ruiseñor (1956), Un rayo de luz (1960), Tómbola (1962) o Canción de juventud (1962) bajo la dirección de Luis Lucía (Cebollada y Rubio, 1996; Mira, 2010).

Junto a los géneros anteriores se empezarán a observar los primeros trabajos con un indudable sentido crítico e innovador, una disidencia interna que pretendía mostrar al espectador la verdadera situación social de la época, alimentándose de una clara influencia neorrealista y rompiendo con el universo habitual que definía el cine en esos años. El impacto decisivo lo provocará José Antonio Nieves Conde con Surcos (1951), abriendo un modelo de discurso que seguirán brillantemente las posteriores obras de Luis García Berlanga con Bienvenido Mr. Marshall (1953), y Juan Antonio Bardem en Muerte de un ciclista (1955) y Calle Mayor (1957); profundizando todas ellas en las miserias y desigualdades de la sociedad española durante el franquismo (Caparrós, 2007: 83-87; Monterde y Riambau, 1996: 183-234).

\section{El renacimiento del fútbol como espectáculo de masas}

Cuando la guerra civil terminó, el panorama del fútbol nacional era tan sombrío como el horizonte general del país. Algunos campos, como el del Oviedo, estaban destruidos, bastantes jugadores habían elegido la vía del exilio, y casi todos los clubs de ciudades que quedaron en zona republicana estaban sin directiva, pues las anteriores habían sido convenientemente "depuradas"1.

La cita anterior muestra claramente cuál era la situación del fútbol español durante la inmediata postguerra, en un periodo que se caracterizará por el intento de Falange Española Tradicionalista (FET) de controlar la actividad deportiva y donde valores tradicionalmente masculinos como la virilidad, la impetuosidad y la furia, serán rápidamente aplicados al fútbol (Polo del Barrio, 1993: 322-369). 
Pero desde los años cincuenta, el proyecto deportivo de FET iniciará a mostrar importantes signos de debilidad y carencias ante la falta de suficientes inversiones económicas e infraestructuras deportivas, que permitieran atraer y direccionar a las masas a través de una actividad física y deportiva convenientemente ideologizada. En cambio, mientras gran parte de la población española seguía alejada de la práctica deportiva, miles de aficionados comenzarán a acudir en tropel a los estadios para disfrutar de las grandes estrellas futbolísticas. Era un país de espectadores deportivos, que definitivamente había convertido el fútbol en un verdadero fenómeno social (Fernández, 1990; Bahamonde, 2002; Bielsa, 2003; Santacana, 2006).

La llegada de jugadores extranjeros como Kubala, Ferenc Puskas y Di Stéfano transformará radicalmente el panorama, marcando el inicio de un nuevo periodo de éxitos internacionales para los principales clubes españoles. El Régimen será consciente desde los años cincuenta del potencial que tenía el fútbol como elemento de desmovilización política, debido principalmente al impacto social que supondrá el éxito conseguido por la selección en el Mundial de Brasil en 1950 y su inesperada victoria frente a Inglaterra (Shaw, 1987: 103-104).

Gracias a su enorme popularidad, el fútbol se convertirá en un pilar de la cultura de evasión del franquismo, que no sólo se reflejará en el aumento del número de espectadores que pagaban por ver los partidos en los estadios, sino también en la integración de esta actividad en el tejido social y en la vida diaria de los españoles.

Gran culpa de las proporciones que alcanzará este proceso la tendrán Kubala y Di Stéfano. La contratación de ambos jugadores supuso la revolución del contexto futbolístico que vivía España, mostrando a otros clubes la importancia que tenía la contratación de una figura extranjera para abrir el camino del éxito (Castillo, 1993; Luque y Finestres, 2006; González Calleja, 2010).

\section{Cine, fúbol y anticomunismo en Los ases buscan la paz}

En 1954 José Ruiz-Castillo se enfrentará al desafío de llevar al cine la vida de Kubala, después de un amplio recorrido como director que le había obligado a transitar desde unos innovadores inicios con trabajos como el de Las inquietudes de Shanti Andia (1947), a evolucionar posteriormente hacia la realización de películas con temáticas más populares y con mayor éxito en las taquillas. Ejemplos de su obra serán largometrajes como el melodrama Obsesión (1947), una historia religiosa como La manigua sin Dios (1948), junto con los obligados temas folclóricos que aparecían en María Antonia, 'La Caramba' (1950), y la biografía histórica de Catalina de Inglaterra (1951). Pero su éxito llegará con El santuario no se rinde (1949), en la línea de las temáticas oficiales del franquismo que apostaban por el cine heroico de exaltación nacionalista de la guerra civil.

En Los ases buscan la paz Ruiz-Castillo realizará un recorrido por la biografía de Kubala, desde su infancia en la Hungría comunista hasta su "liberación" en la España de Franco. La acción de la película se inicia en los momentos previos al comienzo del partido entre la selecciones española y turca en el estadio Olímpico de 
Roma, encuentro correspondiente a la eliminatoria de desempate para la clasificación del Mundial de 1954. En el vestuario, Kubala recibe un telegrama de la FIFA prohibiéndole jugar. El representante de la Federación Húngara, una especie de comisario político-deportivo que perseguirá al futbolista incansablemente a lo largo de la película, tratará de chantajearlo recordándole que todos los problemas podrían terminar si se arrepentía y regresaba a su país. Sus compañeros saltan al terreno de juego mientras él observa varias fotografías de su familia que le recuerdan los difíciles momentos que había tenido que pasar. El inmediato flash-back transporta al espectador a la infancia de Kubala, para descubrir sus duros inicios en el mundo del fútbol, la humilde situación económica de su familia, junto con su matrimonio y los primeros éxitos a nivel profesional.

Su brillante carrera comenzará a complicarse cuando las autoridades comunistas le obliguen a realizar "actividades informativas" para el gobierno, aprovechando la gira que iba a realizar con la selección húngara en Italia. El protagonista no cederá a las presiones negándose a actuar como informador, por lo que será castigado apartándole del equipo. No se han podido verificar la realidad de estos hechos a través de

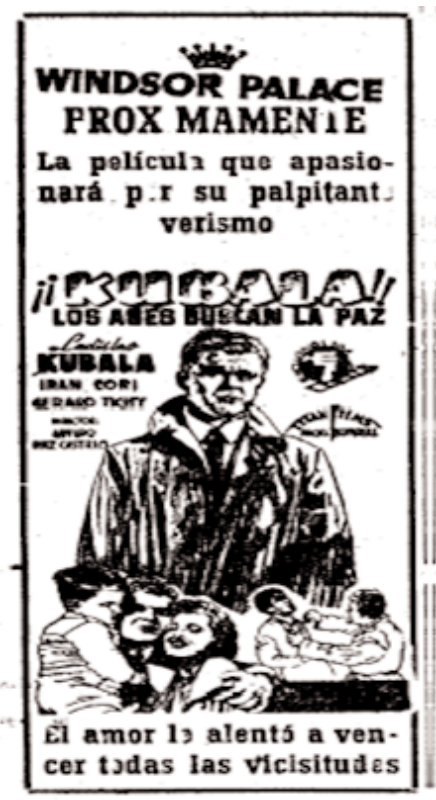
otras fuentes, por lo que posiblemente formen parte de los muchos elementos que el guión modificará conscientemente de la biografía del futbolista. Ante esta situación límite, Kubala decidirá fugarse del país separándose de su familia. Disfrazado de militar ruso cruzará por la frontera austriaca hasta Viena, para concluir su largo viaje en Italia. La FIFA le negará posteriormente el permiso para firmar por algún club italiano, limitándole las posibilidades de continuar su carrera deportiva y abocándole a la miseria. Fedor, el simpático y parlanchín soldado ruso que había acompañado a Kubala en su fuga, interpretado brillantemente por Antonio Ozores, será el que consiga organizar un equipo de exiliados, el Hungaria, con el que intentarán sobrevivir jugando partidos de exhibición por toda Europa.

\section{El Mundo Deportivo, 1 de enero de 1955}

El guión se recrea en los momentos más dramáticos, mostrando un protagonista que no desfallecerá ante las múltiples dificultades que las autoridades comunistas le pongan en su camino. Un modelo ideal para la sociedad española tendría que tener en la familia uno de sus principales valores, por lo que Kubala también representará brillantemente al padre que luchará contra las adversidades para conseguir reunirse con su familia y alcanzar la felicidad. Felicidad que sólo podrá encontrar cuando llegue a Barcelona.

La narración volverá al presente, con el protagonista reencontrándose al final del partido con sus antiguos amigos con los que años antes había escapado de Hungría. 
Una vez más, el comisario político volverá a tentar a Lazslo entregándole un billete de avión, y ofreciéndole regresar a su país para reunirse con su madre a la que no veía desde su fuga. Pero Kubala, tras despedirse de sus amigos con los que había compartido los momentos más difíciles de su vida, permanecerá fiel a su país de acogida volviendo con la selección nacional rumbo a España. Una vez más, la trama pondrá al protagonista ante una difícil elección: ceder a las presiones o permanecer leal a sus principios, Hungría o España, comunismo o libertad, madre o familia.

Kubala se presentará como el prototipo de deportista ideal, ejemplar por sus virtudes y valores dentro y fuera del terreno de juego. El filme nos llevará a lo largo de una vida de sufrimientos y dificultades, que sólo una persona de su entereza moral podría afrontar. Superará sus humildes orígenes y la muerte de su padre, para posteriormente enfrentarse a la opresión del gobierno húngaro. Rubio con ojos azules, atlético, deseado por las mujeres y admirado por los hombres. Ruiz Castillo utilizará inteligentemente el "fenómeno Kubala", mostrando un personaje humilde, luchador y trabajador. Modelo de hijo, que desde niño luchará por sacarles de la pobreza; al mismo tiempo que modelo de marido y de padre, con gran sentido de la lealtad y de la amistad que no descansará hasta hacer realidad el reencuentro con su mujer y su hijo Branco. En definitiva, la imagen perfecta en la que debía proyectarse la sociedad española. Como recordará Méndez Leite, la película brindaba una "magnífica oportunidad al ídolo de las masas de demostrar su categoría como ser humano, patriota y amante de la familia, todo corazón y bondad, que se muestra agradecido al país que le ha permitido rehacer su vida" (1956: 197).

El mensaje político será contundente. La exaltación de Kubala, personificando en su imagen el conjunto de valores que el franquismo reconocía como propios de un ídolo de masas; junto con la reiterada crítica al sistema comunista, representación de una ideología que coartaba los derechos y libertades de sus ciudadanos, frente a la imagen idílica de España, tierra de paz y progreso. Dos argumentos que se verán reflejados en la contraposición entre el temido comisario político y Kubala. Al primero de ellos nunca se le mencionará por su nombre, el director tratará conscientemente de deshumanizarlo, buscando que el espectador relacionase al "diablo rojo" con los complots e intrigas que perseguirán al protagonista. Las nefastas consecuencias que provocaba la relación con el comunismo, también se mostrarán en varios de los personajes que aparecen en la película. Erika, la bailarina que gracias al dinero de Kubala podrá unirse a la fuga y dejar un país que no la ofrecía ningún futuro en su carrera como artista. Kolber, el ex futbolista, antigua estrella del balón, que el sistema comunista también había tratado de utilizar y que llegará a sacrificar su vida por salvar a sus amigos. El Barón Von Saufem, representante de la antigua aristocracia austro-húngara a la que el comunismo le había obligado a exiliarse perdiendo sus riquezas. Todo lo que representan se puede resumir en las palabras de Fedor, el soldado ruso que contestaba a Kubala sobre los motivos que habían provocado su decisión de salir del país: "Me he cansado amigo. Diez años en filas, alimentándome de rancho, tengo tal hambre que me tragaría un niño crudo". 


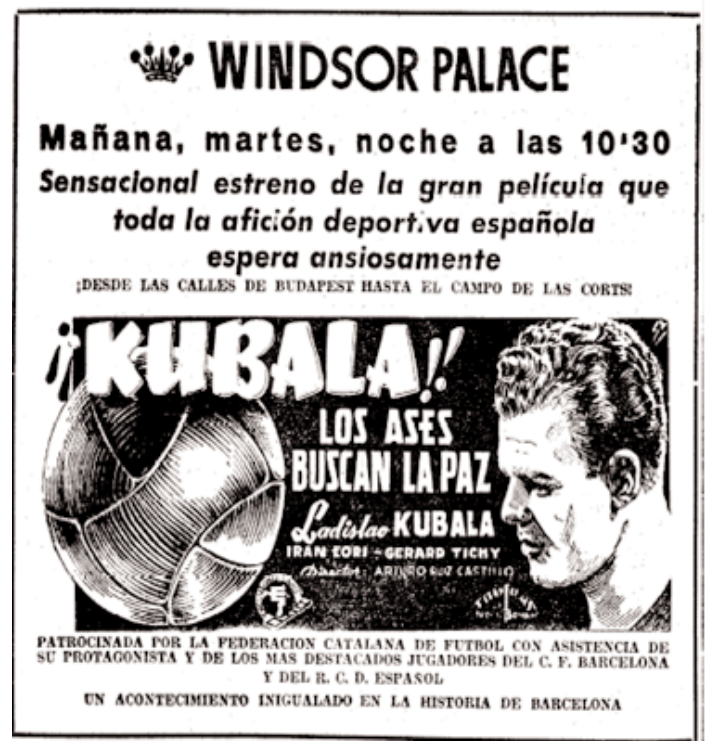

El Mundo Deportivo, 3 de enero de 1955.

Los ases buscan la paz se estrenará en Barcelona el 5 de enero de 1955 en el cine Windsord Palace, con la presencia de Kubala y varios jugadores del FC Barcelona y del RCD Español. La película será producida por Titán Films y Antonio Bofarull, distribuida por Exclusivas Simó y con el patrocinio de la Federación Catalana de Fútbol. El propio protagonista mencionará respecto a su participación en el filme, que nunca había pensado en ser "artista de cine", pese a que el cine había sido "su mejor pasatiempo". Recordaba a la prensa antes del estreno, que en España fue donde "pude reunirme con mi familia, y en donde he hallado una confortable paz [...]", añadiendo que su participación en el rodaje no le había "distraído ni un solo día de entreno". Por último, se dirigirá a los aficionados pidiéndoles que no vieran "en mi actuación cinematográfica nada más que un deseo de corresponder a una oportunidad que se me ofreció para divulgar mi vida deportiva" (El Mundo Deportivo, 5 de enero de 1955).

Al día siguiente, Sáenz Guerrero en La Vanguardia encontraba perfectamente lícito que el cine buscase personajes de la popularidad de Kubala para conseguir atraer el público a las salas, pero criticará que la película, que según su opinión no pasará a las "antologías" cinematográfica, no había conseguido aprovechar el dramatismo "de la manera esperada", quedándose "en una tierra de nadie, donde los fragmentos de partidos de fútbol están montados al aire, sin la imprescindible relación emocional con el personaje y su situación", y donde los diferentes episodios que aparecen "carecen rigurosamente de autenticidad", dentro de una biografía que es "auténtica en la raíz" pero "fantaseada en el detalle" (6 de enero de 1955). En cambio, El Mundo Deportivo consideraba que la película contaba con "valores emotivos y cinematográficos suficientes para que en modo alguno pueda ser consi- 
derado como un mero golpe de audacia comercial". El diario deportivo barcelonés destacaba la "ponderación" de su desarrollo, la "sinceridad de la exposición" y la "total ausencia de excesos efectivistas", con lo que conseguían captar la atención del espectador y llegando "muy finamente a su sensibilidad". Respecto a las secuencias futbolísticas, elogiaba que habían sido "intercaladas en el relato con manifiesta pericia $[\ldots]$ ", y en cuanto a la actuación de Kubala, los periódicos coincidían en resaltar una actuación admirable "a la misma altura que sus compañeros de reparto", desarrollada "sobriamente" y con "excelente naturalidad" (7 de enero de 1955).

El Windsord Palace mantendrá la película en cartelera durante tres semanas y tratará de promocionar la cinta y atraer a los espectadores mediante el sorteo de balones de fútbol firmados por el protagonista en varias "jornadas juveniles" ( $E l$ Mundo Deportivo, 17 enero 1955). El cine Pelayo también proyectará el filme en Barcelona, contando en su estreno con la presencia de Kubala y las actrices Iran Eory y Carolina Giménez (La Vanguardia, 30 de enero 55). En Madrid los espectadores tendrán que esperar al 5 de abril, el "sábado de gloria", como anunciaban los carteles publicitarios, para que el cine Capitol estrene la película en sus tres sesiones diarias, manteniéndose durante dos fines de semana en la cartelera hasta ser sustituida el 24 de abril por Candilejas (ABC, 9 de abril de 1955). Los cines Ideal, Luchana y Benlliure también reestrenarán en la capital la película, permaneciendo en las pantallas hasta principios de mayo.

\section{De La Saeta Rubia a La batalla del domingo: principio y fin de una estrella.}

En 1956 Javier Setó dirigirá Saeta rubia, el primero de los dos proyectos cinematográficos en los que participará Alfredo Di Stéfano. Setó todavía era un joven director de cine con pocas películas en su bagaje profesional, entre las que se podían destacar títulos como Mercado prohibido (1952), Fantasía española (1953) o Mañana cuando amanezca (1955), pero que tendrá una fulgurante carrera posterior en la que llegará a dirigir 25 películas hasta su fallecimiento en un accidente automovilístico en 1969 con tan solo 43 años. Después de Saeta rubia, dirigirá otros interesantes filmes como El valle de las espadas (1963), La llamada (1965), Fugitivos de las islas del sur (1966) o Viaje al vacio (1969) (Rentero, 2006: 481).

El mismo año del estreno de Saeta rubia, el Real Madrid se había proclamado campeón de la primera edición de la Copa de Europa, después de vencer en el estadio del Parque de los Príncipes París al Stade de Reims por 4-3. Al día siguiente de la victoria, el periódico deportivo francés $L$ 'Equipe describirá a Di Stéfano como "el más completo jugador que jamás hayamos visto, tan buen defensor como atacante, ha eclipsado completamente a Kopa" (Bahamonde, 2002: 237). Al mismo tiempo, el club había acelerado los trámites para conseguir la deseada nacionalización del jugador.

En la cúspide del éxito deportivo y del reconocimiento social, la productora Unión Films entenderá que era el momento más adecuado para aprovechar la imagen de Di Stéfano en una película. Al igual que había ocurrido previamente con Kubala, 
los nuevos ídolos de masas serán durante estos años reiteradamente utilizados por el cine como reclamo perfecto para atraer público a las salas. Jesús María de Arozamena y Antonio Mas-Guindal, guionistas de Saeta Rubia, tratarán de explotar la imagen de un actor principal que junto a sus grandes virtudes como deportista, también mostraba una gran sensibilidad ante el sufrimiento de los más necesitados, dejando patente que sus valores cristianos estaban a la misma altura que su prestigio con el balón en los pies.

Un grupo de golfillos de barrio simulan un atropello para robarle la cartera al conductor. Enterados posteriormente que su propietario era el famoso futbolista Alfredo Di Stéfano, tratarán por todos los medios de conseguir devolverle la cartera a su ídolo. Gracias a Doña María, la mujer de Di Stéfano que interpreta en la ficción Mary Lamar, el jugador comienza a descubrir la cruda realidad de la vida de estos muchachos en los arrabales de Madrid. Días después, el robo de una radio con la que querían escuchar el partido del Real Madrid les terminará llevando a todos frente a la justicia. Al enterarse Di Stéfano, acudirá al juez para conseguir la libertad de los chicos a cambio de su compromiso para crear un equipo-el Saeta-, con el que tratar de enseñarles a jugar al fútbol a los muchachos del barrio y alejarles de los peligros de las calles.

Al mismo tiempo, Julia Rey, la cantante y antigua novia del futbolista, aparece en su vida para ofrecerle el rodaje de una película que protagonizarían los dos, poniendo en peligro desde ese momento su relación matrimonial y el futuro del equipo. Andrés, el "Chispa" y los demás golfillos interferirán en la relación entre la cantante y el futbolista, evitando la realización del filme y dando al traste con el posible romance. Con el matrimonio fuera de peligro, y aclarado el malentendido entre los muchachos y Di Stéfano, el Saeta conseguirá ganar el campeonato infantil mientras la estrella del Real Madrid lograba su primera Copa de Europa.

El guión muestra un protagonista que pese a su popularidad no duda en ayudar a los más desfavorecidos, describiendo un "San Francisco" del fútbol que igual invita a comer a los muchachos en su casa, que organiza un equipo al que le regala camisetas y botas, o que llega incluso a aprovechar su influencia social para encontrarles trabajo a todos. Como ocurría en Los ases buscan la paz con Kubala, la relación familiar también ocupará un lugar fundamental en la vida de Di Stéfano, describiendo un matrimonio perfecto en el que la mujer se encargaba del cuidado del hogar y aceptaba con paciencia las posibles infidelidades de su marido, mientras le animaba a "salvar" de la miseria a todos los niños. Pero el destino, y sobre todo los encantos de Julia Rey, pondrán a prueba la ética del héroe. La bella cantante rompecorazones que miente, bebe y fuma, la mujer fatal que tratará de seducir al futbolista, obligando a Di Stéfano a elegir entre las aventuras sentimentales y el proyecto cinematográfico, o la fidelidad conyugal y su responsabilidad frente a los muchachos.

Entre las múltiples escenas reales de partidos que aparecen a lo largo de la película, el espectador irá descubriendo un modelo de héroe cinematográfico compasivo y bondadoso, al mismo tiempo que pasional y seductor, que no dudará en socorrer desde el primer momento a los muchachos y a sus familias. Es interesante destacar la contraposición que realiza Setó entre la vida acomodada del futbolista y su mujer, 
con la miseria de los suburbios de la España franquista en donde los muchachos tienen que sobrevivir. Deudor del neorrealismo italiano, el director se aprovechará del inocente argumento de la película y de sus múltiples situaciones cómicas, para atreverse a mostrar las tremendas desigualdades que existían en la sociedad española de los años cincuenta.

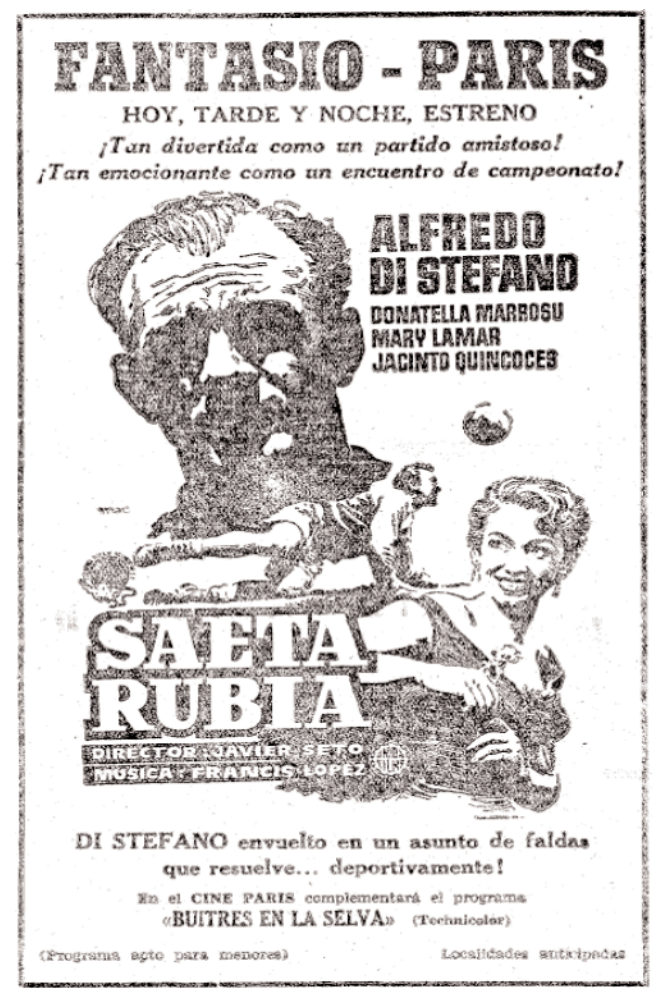

La Vanguardia, 11 de enero de 1957

Pese a su simple base argumental, algunas de las críticas que recibirá la película apuntarán a que hubiera sido mejor si "los elementos de documental hubieran constituido la dominante, aun hilvanados en un leve argumento". El crítico de cine de $A B C$, encontraba más interesante el haber tratado de aumentar el número de escenas futbolísticas sacadas del No-Do en las que aparecía Di Stéfano, dado que los espectadores "a quien desean ver es al excepcional futbolista y no al improvisado actor cinematográfico" (4 de diciembre de 1956). "La película de los deportistas", como la definirá El Mundo Deportivo, permitía ver a Di Stéfano protagonizando una "divertida y emocionante comedia deportiva [...]" (10 de enero de 1957), en la que "con soltura de profesional" representaba "el papel de un deportista nato; dinámico, humano", al mismo tiempo que se intercalaba "la más brillante sucesión de jugadas maestras" (11 de enero de 1957).

A principios de diciembre de 1956, aprovechando la llegada de las fiestas navideñas, se estrenará en los cines madrileños la película. Actualidades y Beatriz serán las salas de cine en las que inicialmente se proyectará el filme, manteniéndose en la cartelera durante las dos semanas siguientes, concretamente hasta el domingo día 16. El propio jugador declaraba a la prensa respecto a su experiencia como actor, que era más fácil ganar dinero en el cine que en el fútbol, "pero más aburrido", recordando que el guión era la historia de un futbolista, "yo, y unos chicos de la calle, que son unos sinvergüenzas y los quiero reformar por el deporte" (La Vanguardia, 25 de mayo de 1956). En Barcelona, Saeta Rubia se estrenará en los cines Fantasio y París el 11 de enero de 1957, manteniéndose en cartelera sólo durante la semana siguiente. En las salas de reestreno se proyectará desde mayo de 1957 en los cines Avenida, Ramblas, Roxi y Triana. 


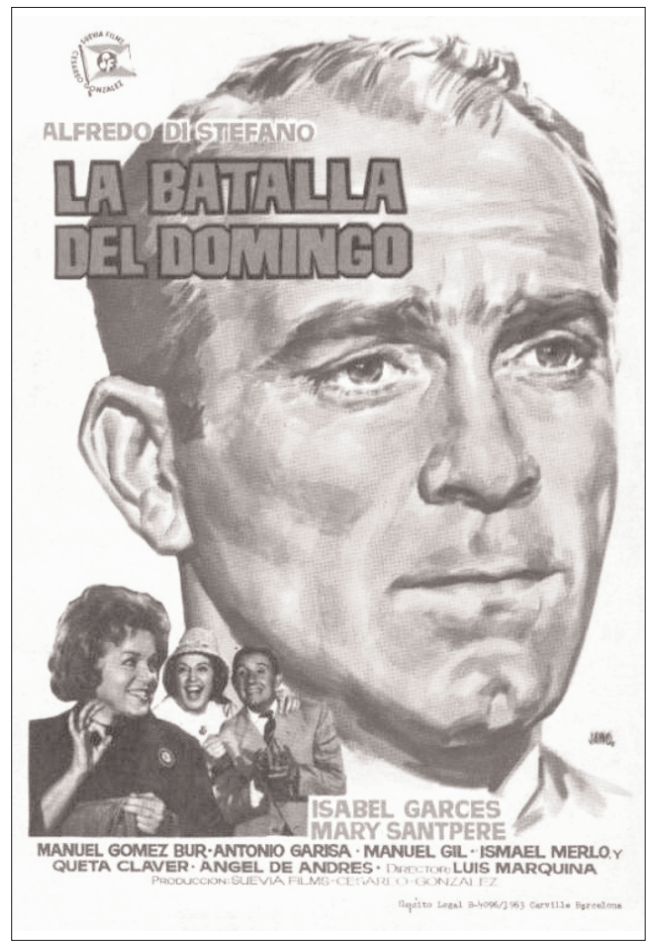

A principios de los años sesenta Di Stéfano se encontraba en el final de su carrera futbolística. Su último partido oficial con el Real Madrid lo disputará en la final de la Copa de Europa en mayo de 1964, cayendo derrotado contra el Inter de Milán por 3-1. El club había conquistado cinco copas de Europa consecutivas y Di Stéfano se había convertido en el motor de un equipo triunfal. Luis Marquina ofrecerá al futbolista en 1962 la posibilidad de volver a interpretarse a sí mismo en La batalla del domingo, junto a un reparto de actores del prestigio de Mary Santpere, Isabel Garcés, Manuel Gómez Bur, Ismael Merlo o Antonio Garisa.

El filme estará producido por Cesáreo González y Suevia Films (Durán, 2003; Castro de Paz, 2005), con un guión realizado por el propio Marquina junto a José Vicente López Rubio y Luis Puente. El Real Madrid cederá nuevamente sus instalaciones y la imagen de sus jugadores para grabar una comedia ligera de enredos, basada en la supuesta manipulación de una productora americana que quería utilizar a Di Stéfano en una película, pero que finalmente servirá de homenaje cinematográfico a la estrella del fútbol. Es interesante analizar brevemente esta obra, en la que ya no encontraremos al joven y atractivo futbolista de principios de los años cincuenta que aparecía en Saeta rubia, para descubrir ahora a un veterano Di Stéfano, que irá rememorando a lo largo de toda la película los momentos más importantes de su exitosa carrera futbolística.

Es la imagen perfecta del padre de familia, pendiente de su mujer y sus hijos, que aconseja y orienta a sus compañeros para que no arruinen su carrera profesional por el peligro de la fama y las mujeres. Ejemplo de profesionalidad y dedicación, estará más cercano a la imagen de austeridad y sacrificio del "monje-soldado" (González, 2005).

\section{A modo de conclusión}

Los años cincuenta se convertirán en el periodo más prolífico para el cine relacionado con la temática futbolística. Cine y fútbol serán las dos principales actividades de ocio de las clases populares durante el franquismo, animadas durante esta década por una coyuntura muy favorable al impulso de esa estrecha relación, al 
coincidir el auge de la industria cinematográfica con uno de los periodos de mayores éxitos de la historia del fútbol en nuestro país. Durante estos años el cine vive uno de sus periodos de mayor esplendor, con salas llenas de espectadores que transforman esta industria en un fructífero negocio, al mismo tiempo que surgen directores como Berlanga o Bardem que comienzan a mostrar sus películas en los principales festivales internacionales. Mientras tanto, el balompié veía renovarse la histórica rivalidad entre el FC Barcelona y el Real Madrid, personalizada en nuevos ídolos de masas como Kubala y Di Stéfano. Al mismo tiempo, la selección española lograba el quinto puesto en el Mundial de 1950 y su posterior victoria en el Campeonato de Europa de Naciones de 1964 ante la mismísima Unión Soviética, junto con las mencionadas cinco copas de Europa del club madrileño.

El fútbol, al igual que también ocurrirá con los toros, se convertirá en uno de los géneros cinematográficos más utilizados en el franquismo. Era perfectamente entendible que el cine aprovechará la transformación del fútbol en un deporte de masas para producir filmes sencillos, que irían desde las comedias costumbristas a los dramas intensos con una fuerte carga ética (Monterde, 2005:275).

Es este último concepto el que con mayor reiteración aparecerá utilizado en los dos filmes analizados. Los héroes del deporte se convierten en modelos de ciudadanos para las plateas, a los que el éxito profesional no les impide mostrar su lado más humano. Ayudan a los más necesitados y muestran la importancia de la unión familiar como en Saeta rubia, mientras que la vida les pone ante la amenaza de los peligros del dinero y las mujeres, demostrando sus fuertes principios morales. Prototipos de éxito y masculinidad, admirados por hombres y mujeres, pero que siempre encuentran la felicidad en el hogar, junto a su mujer y los hijos.

Pero el fenómeno de la utilización del ídolo futbolístico por parte del cine y su transformación en un ejemplo para la sociedad, también se producirá durante estos años, con sus específicas características, en otros países. En Italia, el jugador de fútbol se convierte rápidamente en un imán para las cámaras de cine en un proceso muy similar al español, provocando la aparición de títulos como Undici uomini e un pallone (1948) o La domenica della buona gente (1948), pero será Gli eroi della domenica (1952) del director Mario Camerini la que alcance mayor éxito. En Inglaterra, donde el peso de la tradición futbolística siempre ha sido insuperable, habrá múltiples acercamientos desde las primeras décadas del siglo XX, destacando filmes como The Arsenal Stadium Mistery (1939) y The Stars Look Down (1940), o la interesante The Winning Goal (1920), en la que se interpretaba a sí miso el famoso delantero John Gilbert "Jack" Cock, quien llegará a jugar en equipos como el Huddersfield, Chelsea, Everton y Millwall, y que en 1930 volverá a participar como actor en The Great Game (Sánchez, 2004: 220-223).

Tampoco el cine se olvidará de los ídolos del fútbol al otro lado del océano. Será sobre todo en Argentina y Brasil donde tratarán de glosar las heroicidades de sus estrellas utilizando el impacto del cine. La intensidad con la que los argentinos viven el fútbol se reflejará en Pelota de trapo (1948), y en su segunda parte, Pelota de cuero (1963), en las que tratarán desde un gran dramatismo los múltiples problemas a los que tendría que hacer frente un joven chico de barrio para llegar a jugar en la 
primera división. Ambientes similares también se encuentran los héroes del balón en películas como El hijo del crack (1953), El crack (1959) o El centroforward murió al amanecer (1961). Por otro lado, los directores de cine brasileños también encontrarán en el fútbol y en sus estrellas temas para sus películas, con ejemplos tan tempranos como O campeao do futebol (1931), siendo imprescindible destacar el documental Garrincha, alegria do povo (1962) en el que el director Joaquim Pedro de Andrade, representante del cinema novo brasileño (Sánchez, 2002), realizará un brillante homenaje a Garrincha después del Mundial de Chile en 1962. También es obligado destacar el filme húngaro A Csodacsatar (1956), dirigido por Márton Keleti y que contará con la actuación como actor protagonista del jugador Ferenc Puskas, antes de su fuga del régimen comunista y la posterior llegada a la España, repitiendo una experiencia muy similar a la que había vivido años antes Kubala.

El Régimen sabrá sacar provecho de manifestaciones de la cultura popular como el fútbol y el cine, dando forma un género cinematográfico que les permitirá conjugar la propaganda política, con la ficción y la modificación de las biografías de las estrellas balompédicas, junto con la comedia blanda y amable, al mismo tiempo que ausente de crítica social, en la que el fútbol aparece como el medio ideal para ascender socialmente. Kubala y Di Stéfano tratarán de ganar el partido al cine, a través de retratos edulcorados de sus vidas en los que mostraban la unión perfecta entre el héroe del balón y el ejemplar ciudadano franquista.

\section{Bibliografía}

$A B C$, 9-04-55 / 4-12-56.

BAHAMONDE MAGRO, A. (2002). El Real Madrid en la historia de España. Madrid: Taurus.

BIELSA, R. (2003). La Delegación Nacional de Deportes 1943-1975. (Tesis doctoral no publicada). Universidad de Extremadura.

CAPARRÓS LERA, J. M. (2007). Historia del cine español. Madrid: T\&B Editores.

CASTILLO, J. J. (1993). Kubala: el fútbol es mi vida. Biografía de un mito. Barcelona: El Mundo Deportivo.

CASTRO DE PAZ, J. L. (2005). Suevia Films-Cesáreo González: treinta años de cine español. Galicia: Xunta de Galicia.

CEBOlladA, P.; RUBIO GIL, L. (1996). Enciclopedia del cine español. Cronología. Tomo 1. Barcelona, Ediciones del Serbal.

DURÁN, J. A. (2003). Cesáreo González, el empresario-espectáculo: viaje al taller de cine, fútbol y varietés del general Franco. Pontevedra: Diputación Provincial de Pontevedra.

El Mundo Deportivo, 5-01-55 / 7-01-55 / 17-01-55 / 10-01-57 / 11-01-57.

FERNÁNDEZ SANTANDER, C. (1990). El fútbol durante la guerra civil y el franquismo. Madrid: San Martín.

FILMOTECA ESPAÑOLA (2003). El cine español en los años 50, 50 años de la Filmoteca Española: sede Filmoteca Española, Palacio de Perales, 11 de junio 2003. Madrid: Sociedad Estatal de Conmemoraciones Culturales. 
GISBERT, P. (2002). "Futbol y cine. Un matrimonio imposible". En: Archivos de la Filmoteca, revista de estudios históricos sobre la imagen, $\mathrm{n}^{\circ} 40$, febrero, Valencia: Institut Valencià de Cinematografía Ricardo Muñoz Suay, p.148-163.

GONZÁLEZ AJA, T. (2005). "Monje y soldado. La imagen masculina durante el franquismo". En: Revista Internacional de Ciencias del Deporte (RICYDE), n 1, octubre, pp. 64-83.

GONZÁLEZ CALLEJA, E. (2010). “El Real Madrid, ¿`Equipo del Régimen'? Fútbol y política durante el Franquismo". En: Esporte e Sociedade, n' 14, marzo, on-line.

GONZÁLEZ LEDESMA, F. (1978). Zamora: mito y realidad del mejor guardameta del mundo. Barcelona: Bruguera.

HERRERA NAVARRO, J. (2005). El cine en su historia: Manuel de Recursos Bibliográficos e Internet. Madrid: Arco-Libros.

La Vanguardia, 6-01-55 / 30-01-55 / 25-05-56.

LUQUE, X. G.; FINESTRES, J. (2006). El caso Di Stéfano. Barcelona: Península.

MARAÑ́́N, C. (2005). Fútbol y cine: el balompié en la gran pantalla. Madrid: Ocho y Medio.

MÉNDEZ-LEITE, F. (1956). Historia del cine español. Tomo II. Madrid: Rialp.

MIRA NOUSELLES, A. (2010). Historical dictionary of Spanish cinema. Lanham, Maryland: Scarecrow Press.

MONTERDE, J. E. (2005). “Continuismo y disidencia (1951-1962)”. En GUBERN, R. (2005). Historia del cine español. Madrid: Cátedra, p. 239-293.

MONTERDE, J.E; RIAMBAU, E. (coords.) (1996). Historia general del cine. Europa y Asia (1945-1959). Volumen IX. Madrid: Cátedra.

PAYÁN, M. J. (2002). La historia de España a través del cine. Madrid: Cacitel.

POLO DEL BARRIO, J. (1993). El fútbol en Madrid. De actividad lúdica a espectáculo de masas, 1898-1945. (Tesis doctoral no publicada). Universidad Complutense de Madrid.

RENTERO, J. C. (2006). Diccionario de cineastas. Madrid: Ediciones JC.

ROMAGUERA I RAMIÓ, J. (2003). Presencia del deporte en el cine español: una primera aproximación, un primer inventario. Córdoba: Fundación Andalucía Olímpica y Consejo Superior de Deportes.

SÁNCHEZ NORIEGA, J. L. (2002). Historia del cine: teoría y géneros cinematográficos, fotografía y televisión. Madrid: Alianza.

(2004). Diccionario temático del cine. Madrid: Cátedra.

SANTACANA, C. (2006). El Barça y el franquismo: Crónica de unos años decisivos para Cataluña, 1968-1978. Barcelona: Apóstrofe.

SHAW, D. (1987). Fútbol y franquismo. Madrid: Alianza Editorial.

SIMÓN SANJURJO, J. A. (2011). La marea del deporte: fútbol y modernización en los orígenes de la sociedad de masas en España, 1900-1936. (Tesis doctoral no publicada). Universidad Carlos III de Madrid. 


\section{Notas}

1 Ver GONZÁLEZ LEDESMA, F. (1978). Zamora: mito y realidad del mejor guardameta del mundo. Barcelona: Bruguera, p. 211.

\section{El autor}

Juan Antonio Simón Sanjurjo es doctor en Humanidades. Inicia su carrera de investigador en la Universidad Carlos III de Madrid. En la actualidad trabaja en el Centro de Estudios Olímpicos de la Universidad Autónoma de Barcelona (CEOUAB). Sus trabajos se centran en la historia social del deporte, con una especial atención hacia los estudios de los orígenes y desarrollo del fútbol en España, así como de las relaciones entre deporte, política y medios de comunicación durante el franquismo. 